\title{
Exploring the Necessity for Students to Exercise Digital Minimalism While Studying Online: Case of 35 Master Students at the Department of English of Abdelhamid Ibn Badis University, Algeria
}

\author{
Dallel Sarnou \\ The Department of English, Abdelhamid Ibn Badis University, Algeria
}

\begin{abstract}
This study aimed at exploring the philosophy of digital minimalism, and put forward its importance for an effective online learning in higher education during the lockdown. The long quarantine that the COVID 19 pandemic imposed on most countries of the world has brought radical changes in the way schools, colleges and universities operate. In Algerian higher education, creating online platforms for students was the only solution to move on. However, ignoring that most Algerian students often go online for self-entertainment may lead to a failure or an incomplete success of online teaching during this critical period. To investigate this issue, a questionnaire with only open-ended questions was designed and distributed to 35 students of Language and Communication master, at the English department of Abdelhamid Ibn Badis University. The 35 participants were the researcher's students in the classes of e-learning. Results showed that most participants were distracted by social media notifications. Also, it turned out that the 35 students had no idea of what digital minimalism or digital maximalism is. As a matter of fact, it is suggested that before launching online lectures and webinars for our students, it is of paramount importance to guide them during their online existence and to show them how to be digital minimalists.
\end{abstract}

Index Terms — digital minimalism, digital maximalism, higher education, Algeria, social media

\section{INTRODUCTION}

The COVID 19 pandemic has changed the lives of millions of people around the world in an unprecedented way. The extended period of quarantine and lockdown has caused radical alterations in the lifestyle of human beings. Staying at home for long days, isolated from the outer world, has made people think of the online world as an alternative space where they could stay connected with their friends, relatives and life on the outside. As universities, schools and many workplaces closed, teachers, students and workers were asked to carry on teaching, learning and working from their houses through various online platforms. This sudden shift into the virtual space for hours to realize new purposes that were not meant to be linked with the world of internet has brought on new phenomena in various life arenas, including more importantly digital maximalism and internet addiction. The first one refers to the philosophy of accumulating as many advantages as possible from digital technology while the second one might often be the ultimate consequence of digital maximalism if dependence on new technologies and internet is exaggerated.

In less technologically developed countries, this transition has not been easy for people. For instance, in Algeria, Baccalaureate pupils of 2019-2020 class had to watch YouTube videos where teachers, selected by the ministry of education, gave lessons on the parts of the program that remained after schools were closed. As they were not used to this method of teaching, most pupils around the national territory did not follow these lessons on TV or on YouTube, and if they did, they often were distracted by entertainment videos, Facebook notifications or Instagram new posts. Also, most of them preferred to attend private courses.

At the level of higher education, all universities of Algeria had to create online platforms, which were MOODLES, so as teachers upload the remaining lectures of the second semester. However, for Algerian university students, downloading lectures in PDF format was/is as similar as searching the lectures on GOOGLE or on other research engines. Moreover, most Algerian students are more familiar with social media platforms than with educational platforms. The major purpose of most Algerian students' existence online is for self-entertaining. Facebook Instagram, Youtube and TIKTOK, on top of social media networking sites, represent the main virtual spaces where Algerian young people dwell whenever they go online.

In fact, since a decade or so social media has become an integral part of young people's everyday life, and Algerian youths are no exceptions. In the words of J.B. Doshi, social media is remarkably pervasive and most would argue ubiquitous among college students (Doshi, 2011). Nonetheless, the popularity of social media among young people, and 
college or university students must be questioned and deconstructed by educators and teachers. Because young people are often glued to their mobile phones and constantly online for self-entertainment purpose, this frequently causes distraction whenever they want to use internet and their electronic devices for academic reasons. In this regard, and as a university lecturer of blended learning at the English department of Abdelhamid Ibn Badis University (Algeria), the researcher noticed that teaching our students different units through the university's MOODLE only by uploading our lectures in PDF or PPT formats has not been successful. The complaints of many students about the inutility of the university's MOODLE have triggered one's curiosity to question the viability and effectiveness of online learning during the long quarantine of COVID 19 and how social media platforms have taken over other useful and unentertaining virtual spaces, more particularly educational websites. Furthermore, as a teacher of blended learning and online teaching who spends most of her time online, the researcher started learning about and practicing digital minimalism to reduce the negative effects of being online for long hours. As a matter of fact, one has conceived it as imperative to introduce this notion to the students so as to help them overcome being distracted when they have an online class, and to raise their awareness regarding the risks to becoming internet addicts if they are extremely internet and social media dependent.

\section{A. The Statement of the Problem}

The COVID 19 pandemic has imposed new conditions on teachers and their students in Algerian higher education. Creating online platforms for both teachers and students was the only solution to carry on the academic year. However, no consideration was given to the maturity and readiness of our students to learn online. Knowing that most of our students are to a great extent internet-addicts, i.e. they spend long hours surfing the internet without getting bored, must set alarm bells ringing regarding their attentiveness while studying online. Moreover, phenomena like internet distraction and internet addiction must be thought of while proceeding with online teaching/learning during the pandemic.

\section{B. Research Questions}

The following questions were formulated to investigate the issue tackled in this article:

1- Are our students well-focused during an online lesson?

2- Would social media platforms represent a distraction for students whenever they go online to attend an online class?

3- Must our students be introduced to digital minimalism before attending online courses?

\section{Hypotheses}

The present paper probes into the importance of practicing digital minimalism for students while learning online. To answer the aforementioned questions, the researcher theorizes that our students are often not well-focused while attending an online lesson because of the distraction that social media notifications cause. Therefore, it is of paramount importance to introduce the notion of digital minimalism and guide them toward a minimalist effective online existence.

\section{The Significance of the Research}

This study aims at employing a newly explored philosophy, which is 'digital minimalism', and puts forward its importance during a total reliance on online learning in higher education while on a quarantine. Moreover, a major concern in this article is to orientate our students toward a wise, straightforward and austere use of online platforms.

\section{LITERATURE REVIEW}

Digital minimalism as a countercurrent in a technology-dependent world

The word "minimalism" has gained exceptional attention in the past decade. At the origin of this attention lies the growing capitalist world where the idea of 'more luxuries' has become importunate and persistent. Similarly, the increasing dependence on internet and new technologies has become overwhelming mainly in technologydriven societies of the most developed countries. This has caused a rise of voices calling for reducing this dependence on new technologies in the way we live on a daily basis. Calvin Newport is one among these voices. For Newport, his feelings about minimalism started to form in a 2016 blog post where he expressed his concern on his relationship with technology. The young computer science professor at George Town University believes that the recent unprecedented developments of the Internet Era, including the over-dependence on social media and communication tools, have become risky. However, Newport asserts that finding a balance in using new technologies could be the only way for people to stay safe. In his opinion, digital minimalism, as a philosophy, can be one solution to reduce the negative effects of extensive use of new technologies. In fact, minimalists often believe in the desire not just for less stuff, but also for more control and intention in how we spend our time and energy: "Minimalists tend to spend much less money and own many fewer things than their peers. They also tend to be much more intentional and often quite radical in shaping their lives around things that matter to them." This intention is completely missed in our use of technology. In his 2019 bestselling book, Digital Minimalism Choosing a Focused Life in a Noisy World, Newport argues that our culture's relationship with these tools is 
complicated by the fact that they mix harm with benefits. Smartphones, ubiquitous wireless internet, digital platforms that connect billions of people - these are triumphant innovations. (p10)

Newport adds in the next page: "there are the Neo-Luddites, who advocate the abandonment of most new technologies. On another extreme, you have the Quantified Self enthusiasts, who carefully integrate digital devices into all aspects of their life with the goal of optimizing their existence. Of the different philosophies I studied, however, there was one in particular that stood out as a superior answer for those looking to thrive in our current moment of technological overload. I call it digital minimalism, and it applies the belief that less can be more to our relationship with digital tools." (p11) Therefore, for Newport, neither technophobia nor technophilia would make new technologies more useful and people's life more comfortable. Moderation in using internet and modern technologies is, in Newport's opinion, the best way of existing in an extremely technology-driven world.

Taking for granted that new technologies such as social media (SM) and smartphones have massively changed how we live in the twenty-first century, we should, instead of thinking about the unease with new technologies and about if they are useful or not, reconsider our autonomy from total dependence on new technologies and internet. Newport interestingly notices that we signed up for social media services (like Facebook and Instagram) and bought electronic devices (like Androids and IPhones) for minor reasons - to look up friends' relationship statuses or eliminate the need to carry a separate iPod and phone - and then found ourselves, years later, increasingly dominated by their influence, allowing them to control more and more of how we spend our time, how we feel, and how we behave. (p 30) In the second chapter of his book, Newport puts forward that digital minimalism, as a philosophy, is the best way to defeat internet addiction and technology-dependence. He argues that digital minimalism is a philosophy of technology use in which netizens focus their online time on a small number of carefully selected and optimized activities that strongly support things they value, and then happily miss out on everything else. ( p 31) In other words, the idea behind digital minimalism is to help create a strategy for sustainable technology use, starting with a rapid digital discard process, where all optional technologies are avoided for 30 days. Afterwards, each technology is evaluated for the value it serves before introducing it back into one's life, if at all.

The major dilemma caused by the use of new technologies and being a digital maximalist is related to studies and students. In fact, a myriad of recent researches argue that the extensive use and the strong attachment to new technologies and internet definitely cause distraction, losing focus and less concentration mainly for young people. For instance, in a research conducted by Affleck (2007) as cited by Sigman $(2007,176)$, the researcher contends that today's youth have become fragmented in the sense that their attention is drawn by myriad demands on their sensory systems. It is the excessive access to technology and the amount of time which today's learners spend on their electronic devices and in online platforms and to which they have become accustomed, that contribute to these learners not being able to pay attention in the classrooms. (Lindsay Mary Brand, 2010)

In one of the most important books tackling the effect of internet and new technologies on people's thinking and focusing, Nicholas Carr's 2010 book entitled The Shallows - What the Internet is Doing to our Brain, Carr demonstrates that our brains change with every new technology, and he argues that this is not a positive change. He backs up his viewpoint by referring to "dozens of studies by psychologists, neurobiologists, educators, and Web designers [which] point to the same conclusion: when we go online, we enter an environment that promotes cursory reading, hurried and distracted thinking, and superficial learning".(Carr, 2010). Carr, therefore, argues that this conclusion is threatening our ability to engage in "meditative thinking".

In a similar vein, other researchers, like Alison Purvis and Helen Rodger, consider social media as a distraction, a platform which has so much content linked to so many different connections that it quickly distracts users away from their original purpose of visiting or taking the user into a number of unfruitful channels. (Andersson et al., 2013). Purvis, Rodger and Beckingham (2016), in another research, argue that social media often absorbs valuable time (p 02). Therefore, one can contend that different social media platforms rather distract their users even if the latter visit a given social networking sites for studying or looking for information. In this regard,

On another hand, a learner's capacity for attention leading to their ability to concentrate depends on factors which include commitment and enthusiasm for the task, skills at doing the task, emotional and physical state, psychological state, and the learner's educational and home environments. Taking these factors into account during lessons, the teacher needs to ensure that the learner is motivated to attend to the lessons. Learners of today spend many hours making use of technology. This needs to be kept in mind while preparing lessons in order to ensure that the learner's attention is captured and maintained in order for sufficient learning to take place. (Brester and Brand, 2013)

In fact, Algerian students are no exception. With more accessibility to internet $24 / 7$ with the $3 \mathrm{G}$ and $4 \mathrm{G}$ and with more advanced mobile phones and other electronic devices, most of them are glued to their mobile phones. This fact has provoked the researcher's consideration of questioning the extent to which our students would stay focused in our online classes. Therefore, in the paragraphs that follow, a detailed description of the research methodology of this investigation will be presented.

\section{ReSEARCh Methodology}

A. The Design of the Study 
This research work is exploratory since it investigates the cruciality of introducing the notion of digital minimalism to university students to prepare them to spending long hours of online learning during the Covid19 pandemic without being distracted or at least while being focused for longer time. After a two-months experience of teaching via EDMODO -which is a full-featured social learning platform designed to connect and collaborate within the educational environment -35 first year master students of language and communication at the English department of Andelhamid Ibn Badis, the researcher detected that most students were distracted by FACEBOOK and INSTAGRAM notifications and by other alluring applications they have on their electronic devices, most of which are mobile phones. To authenticate what one has noticed, a questionnaire was designed and distributed to the 35 selected students to get their viewpoints. In the next section, more details about the participants and the research tools will be given.

\section{B. Participants and Research Context}

35 first year students of master degree, language and communication specialty were the participants in this investigation. There were 32 female students and only 3 male students. The average age of these students is 21 . The researcher chose this group of students because they are her students and because she teaches them blended learning, a course that required online lectures via a virtual classroom through EDMODO. Moreover, the researcher knows that her students have different social media accounts: INSTAGRAM, FACEBOOK, VIBER, WHATSAPP, SNAPCHAT and other SM platforms. In this sense, these students may represent the majority of university students in Algeria.

During a period of two months, the research was teaching the selected students online via the EDMODO platform. The latter is, to a great extent, like the FACEBOOK in its design. The researcher had to meet the students twice a week to discuss via texting only the topic of each lecture. The time of the online meeting always started at $3 \mathrm{pm}$, and lasted for an hour and a half.

\section{Research Instruments}

The present research is exploratory since it investigates an issue that has not been tackled in previous researches in the Algerian context. Hence, the main research tool that the researcher found most relevant to collect the required data was a questionnaire constituted of 10 questions. All questions of the designed questionnaire were open-ended questions. More details are displayed in the next section.

\section{The Questionnaire: Why Open-ended Questions}

The present research is qualitative since it is primarily exploratory. It essentially relies on data obtained from a firsthand questionnaire sent to my students via Google questionnaires. For the specificity and newness of the issue under investigation, and the necessity to allow the participants to self-express, only open-ended questions were used while designing the questionnaire. This type of questions allows respondents to answer in open text format so that they can answer based on their complete knowledge, feeling, and understanding. It means that the response to every question is not limited to a set of options (Popping, 2015). Because open-ended questions require respondents to formulate a response in their own words and to express it verbally or in writings, the researcher could easily probe deep into the respondent's answers, gaining valuable information about the subject at hand. Moreover, open-ended questions are more suitable than closed-ended questions for measuring knowledge, because they not only minimize the likelihood that respondents will try to guess the right answer but also often yield more reliable and valid information. However, when respondents cannot immediately recall the correct answer, open-ended questions also elicit more "don't know" responses or refusals than closed questions do (see Krosnick \& Presser, 2010)

So, the following are the ten questions that were asked to the students:

Question 1: How many social media accounts do you have? And what are they?

Question2: How much time do you spend on the different social media platforms you are subscribed to?

Question3: Have you enjoyed studying online during the quarantine period?

Question4: Do you feel distracted by the social media notifications while you are studying online? Explain.

Question5: Do you prefer checking your social media accounts or the virtual classroom created by your teacher?

Question6: Do you know what digital maximalism is?

Question7: Do you know what digital minimalism is?

Question 8: Have you ever tried to log out from or deactivate your Facebook or Instagram accounts? If yes, how did you feel afterward?

Question9: Have you ever tried to limit your screen time for a specific purpose?

Question10: Have you ever tried to stay disconnected from the online world for a long period of time?

\section{FINDINGS AND DATA ANALYSIS}

Unlike closed questions, answers to open-ended questions are more difficult to analyze and interpret. However, content analysis is the most used method of analyzing responses to open-ended questions. In fact, content analysis is a research method that is used for analyzing and making inferences from a given text and other forms of qualitative information such as open-ended questions. It uses a variety of analytic strategies to categorize, compare and contrast a 
corpus of data. After receiving the answers of the 35 students, they were categorized them into five sections. In the following chart, the students' answers are displayed into five categories:

\begin{tabular}{|l|l|l|l|l|}
\hline $\begin{array}{l}\text { Social media in the } \\
\text { life of the students }\end{array}$ & $\begin{array}{l}\text { Social media vs. academic } \\
\text { platforms: what do students } \\
\text { prefer? }\end{array}$ & $\begin{array}{l}\text { Internet distraction } \\
\text { during students online } \\
\text { activities }\end{array}$ & $\begin{array}{l}\text { The students and } \\
\text { digital maximalism }\end{array}$ & $\begin{array}{l}\text { The necessity of } \\
\text { introducing } \\
\text { students to digital } \\
\text { minimalism }\end{array}$ \\
\hline Questions 1 and 2 & Questions 3 and 5 Question 4 & Question 6 \\
\hline
\end{tabular}

The chart above represents the different themes that the questions and the students' answer were categorized into. In the next lines, we will present the students' answers upon which conclusions and recommendations will be built in the last section.

\section{A. Social Media in the Life of the Students}

The students' answers were categorized into five themes: the role of social media the life of the students, what students prefer, internet distraction, students' acquaintance with digital minimalism and digital maximalism. From question 1, the researcher confirmed that all students have more than one social media account. Most students have four accounts, Facebook, Instagram, Snapchat and Whatsapp more particularly. Only one student, who is the oldest among this group of students, revealed that she has only a Facebook account through which she stays informed on news related to her studies. As for the students' answers to question 2 concerning the amount of time they spend checking their social media timelines, the average duration was 4 hours a day. One student said she spent 7 hours online on a daily basis. The most common fact that was deduced from the students' answers is that during the quarantine, their screen time increased to more than 8 hours a day mainly during the period of partial lockdown.

\section{B. Social Media vs. Academic Platforms: What Do Students Prefer?}

All students said that they enjoyed studying online through the EDMODO platform. This may go back to the design of this platform, the boredom of the quarantine they wanted to break or to the interesting topics that were discussed throughout the virtual meetings. For question 5, the answers of the students were varied. While ten students said they prefer checking the virtual classroom created by their teacher over checking their social media account(s), fifteen students disclosed that their social media timelines are more appealing and entertaining than the virtual classroom. The remaining students said that they do not have a preference regarding these different platforms since one is educational and the others are personal and for self-entertainment.

\section{Internet Distraction during Students' Online Activities}

The researcher expected that all students would reveal that they feel distracted by social media notifications while studying online; however, there where students who asserted that they do not get distracted by these notifications. Eight students stated that they muted these notifications whenever they went online to attend a virtual meeting with the teacher. For the rest of the students, i.e. 25 students, social media notifications are distracting.

\section{The Students and Digital Maximalism}

Question 6 was tricky and complicated for the students. All students said that they had to type the words 'digital maximalism' on Google to understand the notion to be able to understand it. All the students, after they read different definitions of the aforementioned idea, admitted that they had no idea on what digital maximalism is. This clearly reveals that my students go online anarchically and without predetermined goals.

\section{E. The Necessity of Introducing Students to Digital Minimalism}

Questions 7, 8, 9 and 10 aimed at grabbing the students' attention to the idea of purposeful online existence. By asking them what digital minimalism is, the researcher anticipated that all students would search for this notion on Google as it was known beforehand that the students had no idea regarding this concept. Indeed, all responses to question 7 were negative, i.e. students indicated through their different answers that this was a new notion for them as much as digital maximalism is. Answers for question 8 were miscellaneous; 12 students said that they did deactivate their social media accounts every now and then. 3 students said they did not see this necessary to do, and they never deactivated their accounts. The other students declared that they knew they had to deactivate their social media accounts from time to time mainly during exams; however, they were not able to do it when necessary. The students who said they deactivated their accounts whenever they went online for studying explained that they felt independent and more in control of their online activities.

Answers for question 9 and 10 were surprising and unexpected since 30 students out 35 said that they have never tried to limit their screen time for a specific purpose, and two students confessed that they do not know how to do it. For the other 5 students, they stated that limiting screen time was something they often did mainly during the exam period. One student added that she limited her screen time by uninstalling Facebook and Instagram applications. She explained that by doing so, she felt relieved and self-controlled. Moreover, no student affirmed that they have ever tried to stay disconnected from the online world for a long period of time. Most answers highlighted the importance of the world of internet for their studies. However, one student said that he tried to stay disconnected during two weeks while on a 
quarantine, and yet he could not do it for a longer period. He argued that staying away from the world of internet made his days so boring.

\section{DisCUSSIONS AND CONCLUSIONS}

The previous section presented the students' answers to the questionnaire. Building upon the content analysis of these answers, research results of the present study suggested that introducing the students to the notion of digital minimalism and its tips is required during this period of quarantine. Explaining this philosophy to the students who are digital immigrants is of paramount importance considering the amount of time students spend scrolling down and up in their social media timelines. From the researcher's own experience teaching her students in class, one noticed that many of them get easily distracted by Facebook or Instagram notifications. Therefore, one can infer that they are more distracted by these notifications at home when studying online, and being by their own without the instructor. To help the students control their online time without being distracted and to maximize the benefits of online lectures during this critical period, the following suggestions and tips could be given and explained to the students:

-The students must know how to build a habit of decluttering, i.e. organizing, their devices, and mainly mobile phones: this can be done by eliminating useless applications like those of games.

-Teachers and instructors should advise their students to uninstall social media applications on the device with which they go online to attend virtual classes. For instance, if they are using their mobile phones to study online, they have to delete Facebook and Instagram applications. These can be checked on their computers or laptops.

-An important tip to recommend the students to do is to minimalize their social media accounts. For example, from the students' answers to question 1, it was obvious that most students spend long time on social media because they have more than four social media accounts. In such a case, these students waste much time on checking these accounts instead of studying. As a matter of fact, it is necessary to suggest for students that they would have two social media accounts maximum.

-Another crucial advice to give to the students is to turn off all kinds of notifications whenever they go online to study. This also has to do with reducing one's screen time. For the latter, the teacher can show the students applications and techniques to limit their screen time.

-A last suggestion is for teachers themselves. Teaching online should not prevent teachers to recommend extra readings and offline activities for their students. The teacher must help his/her students to find offline alternatives for the students. For instance teachers of literature can recommend hardcopies of novels to read. For teachers of applied sciences, they ought to recommend real life experiments done by the students who can film themselves doing these experiments and send the videos or podcasts to their instructors.

To conclude, the COVID 19 pandemic and the crises that it has caused could not impede the educational process in most countries of the globe. It is thanks to technology and the world of internet that teachers could continue teaching and that students could carry on learning. However, a total reliance on online teaching may have negative consequences as well. In this paper, the researcher highlighted a major issue related to online teaching during the quarantine, which is social media distraction. This research, therefore, suggested that introducing the students to the notion of digital minimalism could be a crucial solution to help students overcome internet discussion during online classes.

\section{REFERENCES}

[1] Andersson, A., Hatakka, M., Grönlund, Å, and Wiklund, M. (2013). Reclaiming the students - coping with social media in 1:1 schools. Learning, Media and Technology. http://dx.doi.org/10.1080/17439884.2012.756518.

[2] Purvis, A., Rodger, H. and Beckingham, S. (2016). Engagement or distraction: the use of social media for learning in higher education. Student Engagement and Experience Journal, 5 (1).

[3] Bester, B., \& Brand, L. (2013). The effect of technology on learner attention and achievement in the classroom. South African Journal of Education, 33 (2), 1-15.

[4] Brand L. M. (2010). The effect of technology on attention and concentration within the classroom context. MA dissertation. University of South Africa.

[5] Carr, N. G. (2011). The shallows: what the Internet is doing to our brains. Norton pbk. [ed.] New York: W.W. Norton.

[6] Doshi, J. B. (2011). Asking the right questions: A critique of Facebook, social media and libraries. Public Services Quarterly, $102-110$.

[7] Krosnick, J. A., Presser, S. (2010). Question and questionnaire design. In Marsden, P. V., Wright, J. D. (Eds.), Handbook of survey research (2nd ed., pp. 263-313). Bingley, UK: Emerald.

[8] Popping, R. (2015). Bulletin de méthodologie sociologique. BMS 128(1):23-39

[9] Sigman A. (2007). Remotely controlled. How television is damaging our lives. Random House, UK. 


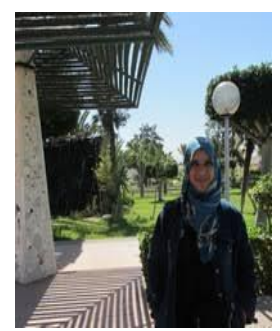

Dallel Sarnou is an associate professor at the department of English (Abdelhamid Ibn Badis University, Algeria). She is specialized in various fields including educational technology, Arab women narratives, Posthumanism, Transhumanism and critical theory. Sarnou has published an important number of academic papers, many poems and two monographs. 